\title{
Review: Plant Binary Vectors of Ti Plasmid in Agrobacterium tumefaciens with a Broad Host-Range Replicon of pRK2, pRi, pSa or pVS1
}

\author{
Norimoto Murai \\ Department of Plant Pathology and Crop Physiology, Louisiana State University and LSU AgCenter, Baton Rouge, USA. \\ Email: nmurai@lsu.edu \\ Received March $7^{\text {th }}, 2013$; revised April $4^{\text {th }}, 2013$; accepted April 13 ${ }^{\text {th }}, 2013$ \\ Copyright (C) 2013 Norimoto Murai. This is an open access article distributed under the Creative Commons Attribution License, \\ which permits unrestricted use, distribution, and reproduction in any medium, provided the original work is properly cited.
}

\begin{abstract}
This review chronicles the development of the plant binary vectors of Ti plasmid in Agrobacterium tumefaciens during the last 30 years. A binary vector strategy was designed in 1983 to separate the T-DNA region in a small plasmid from the virulence genes in avirulent T-DNA-less Ti plasmid. The small plant vectors with the T-DNA region have been simply now called binary Ti vectors. A binary Ti vector consist of a broad host-range replicon for propagation in $A$. tumeraciens, an antibiotic resistance gene for bacterial selection and the T-DNA region that would be transferred to the plant genome via the bacterial virulence machinery. The T-DNA region delimited by the right and left border sequences contains an antibiotic resistance gene for plant selection, reporter gene, and/or any genes of interest. The ColEI replicon was also added to the plasmid backbone to enhance the propagation in Escherichia coli. A general trend in the binary vector development has been to increase the plasmid stability during a long co-cultivation period of $A$. tumefaciens with the target host plant tissues. A second trend is to understand the molecular mechanism of broad host-range replication, and to use it to reduce the size of plasmid for ease in cloning and for higher plasmid yield in $E$. coli. The broad host-range replicon of VS1 was shown to be a choice of replicon over those of pRK2, pRi and pSA because of the superior stability and of small well-defined replicon. Newly developed plant binary vectors pLSU has the small size of plasmid backbone (4566 bp) consisting of VS1 replicon (2654 bp), ColE1 replicon (715 bp), a bacterial kanamycin (999 bp) or tetracycline resistance gene, and the T-DNA region (152 bp).
\end{abstract}

Keywords: Agrobacterium tumefaciens; Binary Vectors; pRK2; pRi; pSA; pVS1; T-DNA; Ti Plasmid

\section{Introduction}

Agrobacterium tumefaciens is a Gram-negative soil bacterium and plant pathogen causing crown gall disease in angiosperms and gymnosperms [1]. Agrobacterium-plant interaction was one of the first model systems in which the molecular mechanism for plant pathogenicity has been elucidated in details [2,3]. About $20 \mathrm{kbp}$ segment of DNA (T-DNA) in a tumor-inducing plasmid (ca. $200 \mathrm{kbp}$ Ti plasmid) is transferred from the bacterium to the host plan genome by a molecular machinery closely resembling to a bacterial conjugal transfer [4-6]. The disease phenotype is a manifestation of expression of bacterial T-DNA genes in plant cells that is over-production of two plant growth hormones, cytokinin and auxin.

This natural DNA transfer system has been exploited to introduce genes of agronomic interest into plants which resulted in the production of genetically modified crops by plant biotechnology campanies. Initial approaches of gene transfer were to introduce a target gene into the T-DNA region of Ti plasmid after either a single-(cointegration) or double-homologous recombination between an intermediate vector (pRK290) and Ti plasmid [7,8]. A binary plant vector strategy was designed to separate the T-DNA region in a small plasmid from the virulence genes in avirulent T-DNA-less Ti plasmid [9]. The small plant vectors with the T-DNA region have been simply now called binary Ti vectors $[10,11]$.

\section{Broad Host-Range Origin of Replication from pRK2 of IncP-1 Incompatibility Group}

Almost all binary vectors used an origin of replication of pRK2 at the beginning of its application (Table 1). pRK2 is a large $56 \mathrm{kbp}$ plasmid of incompatibility group P-1 
Table 1. Overview of plant binary Ti vectors listed based on the broad host-range replicons used for propagation in Agrobacterium tumefaciens and/or Escherichia coli.

\begin{tabular}{|c|c|c|c|c|c|c|c|c|}
\hline $\begin{array}{c}\text { Plant binary } \mathrm{Ti} \\
\text { vectors }\end{array}$ & Year & Size in kbp & $\begin{array}{c}\text { E. coli } \\
\text { Replicon }^{1}\end{array}$ & $\mathrm{Mob}^{2}$ & $\begin{array}{l}\text { Bacterial } \\
\text { selection }^{3}\end{array}$ & $\begin{array}{c}\text { T-DNA borders } \\
\text { (Right/Left) }^{4}\end{array}$ & Plant selection gene $\mathrm{at}^{5}$ & Ref \\
\hline
\end{tabular}

I. IncP-1/pRK2 origin of replication

a) pRK252 10.3 kb-based binary vectors;

$\begin{array}{ccccccccc}\text { pBin19 } & 1984 & 11.8 & \text { pRK2 } & \text { Yes } & \text { kan NPTIII } & \text { nop pTiT37 } & \text { nos:NPTII:nos at RB } & 16 \\ \text { pAGS127 } & 1985 & 15.0 & \text { pRK2 } & \text { Yes } & \text { tet } & \text { oct pTiA6/Ach5 } & \text { nos:NPTII:ocs at RB } & 19 \\ \text { pBI121 } & 1987 & 14.7 & \text { pRK2 } & \text { Yes } & \text { kan NPTIII } & \text { nop pTiT37 } & \text { nos:NPTII:nos at RB } & 17 \\ \text { pBIG } & 1990 & 13.9 & \text { pRK2 } & \text { Yes } & \text { kan NPTIII } & \text { nop pTiT37 } & \text { nos:NPTII or HPT:G7 at RB } & 18\end{array}$

b) pRK290 20.0 kb-based binary vectors;

$\begin{array}{lllllllll}\text { pOCA18 } & 1988 & 24.3 & \text { pRK2 } & \text { Yes } & \text { tet } & \text { oct pTi } & \text { nos:NPTII:ocs at LB } & 21 \\ \text { pJJ1881 } & 1992 & 25.7 & \text { pRK2 } & \text { Yes } & \text { tet } & \text { oct pTiA6/Ach5 } & \text { nos:NPTII or HPT:ocs at LB } & 22\end{array}$

c) pTJS75 7.0 kb-based vectors;

$\begin{array}{ccccccccc}\text { pGA471 } & 1985 & 15.6 & \text { pBR322 } & \text { Yes } & \text { tet } & \text { nop pTiT37 } & \text { nos:NPTII:nos at RB } & 25 \\ \text { pTRA409 } & 1992 & 11.5 & \text { pRK2 } & \text { Yes } & \text { tet } & \text { oct pTi15955 } & \text { tml:NPTII:tml at RB } & 27\end{array}$

d) mini-RK2 replicon-based vectors;

$\begin{array}{ccccccccc}\text { pPCV001 } & 1986 & 9.2 & \text { pBR322 } & \text { Yes } & \text { amp/chl } & \text { pTiC58/B6S3 } & \text { nos:NPTII:ocs at RB } & 28 \\ \text { pCB301 } & 1999 & 5.0 & \text { pRK2 } & \text { No } & \text { kan NPTIII } & \text { nop pTiT37 } & \text { nos:BAR:nos at LB } & 15\end{array}$

\section{II. pRiHRI and ColEI origin of replication}

$\begin{array}{ccccccccc}\text { pC22 } & 1986 & 17.5 & \text { pBR322 } & \text { Yes } & \text { amp/str/spc } & \text { oct pTiB6S3 } & \text { nos:NPTII:nos at RB } & 30 \\ \text { pCGN1547 } & 1990 & 14.4 & \text { pBR322 } & \text { Yes } & \text { gent pPH1JI } & \text { oct pTiA6 } & \text { mas or 35S:NPTII:mas or tml at LB } 31\end{array}$

\section{IncR/pSa origin of replication}

\begin{tabular}{|c|c|c|c|c|c|c|c|c|}
\hline pGreen0029 & 2000 & 4.6 & $\mathrm{pSa}$ & Yes & kan NPTI & nop pTiT37 & nos:NPTII:nos at RB & 32 \\
\hline pSoup & 2000 & 9.3 & pRK2 & No & tet & no & no & 32 \\
\hline pCLEAN-G115 & 2007 & 6.0 & $\mathrm{pSa}$ & Yes & kan NPTI & nop pTi cons & 35S:HPT:nos at LB & 34 \\
\hline pCLEAN-S166 & 2007 & 11.1 & $\mathrm{pSa}$ & No & tet & nop pTi cons & nos:HPT:nos at LB & 34 \\
\hline \multicolumn{9}{|c|}{ V. IncP/pVS1 and ColEI origin of replication } \\
\hline pPZP111 & 1994 & 11.8 & pBR322 & Yes & chl & nop pTiT37 & 35S:NPTII or $a a c C 1: 35 S$ at LB & 39 \\
\hline pPZP211 & 1994 & 11.9 & pBR322 & Yes & $\mathrm{str} / \mathrm{spc}$ & nop pТiT37 & 35S:NPTII or aacC1:35S at LB & 39 \\
\hline pCAMBIA & 1995 & 11.5 & pBR322 & Yes & kan NPTIII & nop pTiT37 & 35S:NPTII or HPT:35S at LB & \\
\hline pLSU2 & 2011 & 6.4 & pUC18 & No & kan NPTI & oct pTi15955 & tml:NPTII or HPT:tml at LB & 43 \\
\hline pLSU12 & 2011 & 6.9 & pUC18 & No & tet & oct pTi15955 & tml:NPTII or HPT:tml at LB & 42 \\
\hline
\end{tabular}

Note: 1: ColEI replicon derived from pBR322 or pUC18 was added to promote the propagation of binary Ti vectors in E. coli; 2: Mobilization (Mob) of binary vectors assisted by pRK2013 from E. coli to A. tumefacience possible (Yes) or not possible (No) by triparental mating; 3: Bacterial selection by antibiotics: chloramphenicol (chl), kanamycin (kan), gentamycin (gen), spectinomycin (spc), streptomycin (str), or tetracycline (tet). Neomycin PhosphoTransferase (NPTI) gene confer the kanamycin resistance in bacteria; 4: The origin of T-DNA border sequences derived from either nopaline (nop) or octopine (oct) type Ti plasmids, nopaline type Ti plasmid consensus border sequence (cons); 5: Plant-expressible selection marker genes, a promoter or terminator sequence derived from nopaline synthase gene (nop), octopine synthetase gene (oct), manopine synthase gene (mas), Cauliflower Mosaic Virus 35S (35S) or Tumor Morphology Large (tml) T-DNA gene. Bialaphos resistance (BAR) gene confers the herbicide glufosinate resistance. Gentamycin Acetyl Transferase (aacC1) gene confers the gentamycin resistance in plants. Hygromycin PhosphoTransferase (HPT) coding regions confer the hygromycin resistance in plants. Neomycin PhosphoTransferase (NPTII) coding regions confer the kanamycin resistance in plants. Location of the plant selection marker gene proximal to either Left Border (LB) or Right Border sequences (RB) was indicated. 
originally isolated from Klebsiella aerogenes [12]. A useful feature of P-1 replicon is an extensive host-range among Gram-negative bacteria. pRK2 is replicated and maintained in Esherichia coli, A. tumefaciens, Sinorhizobium meliloti, Pseudomonas aeruginosa, and others species. Smaller derivatives of pRK2 were generated such as 20.0 kbp pRK290, 11.0 kbp pTJS133, 10.3 kbp pRK252, and $7.0 \mathrm{kbp}$ pTJS75 [13]. Replication of pRK2 derivatives requires 700 bp ori $V$ and $\operatorname{trfA} *$ region, and stable maintenance of these plasmids requires additional regions depending on species. For Agrobacterium, stable maintenance of plasmid in a non-selective condition after 35 generations declined progressively from pRK2 $(100 \%)$ to pTJS133 (96\%), pRK290 (89\%), pTJS75 (57\%) and pRK252 (12\%). The smallest pRK2 derivative pTJS75 has oriV, $\operatorname{trf} A^{*}$, oriT and tetracycline resistance. The most stable derivative pTJS133 in Agrobacterium was generated by addition of $3.1 \mathrm{~kb}$ region containing kor $A$ and $\operatorname{korB}$ to pTJS75. A separate plasmid pRK2013 contains the pRK2 transfer genes, its own mobilization genes and ColE1 replicon, and is used by tri-parental mating to transfer pRK2 plasmids from $E$. coli to A. tumefaciens. Thus, the major limitation of pRK2-derived plasmids to be used for the binary vectors are the large multi-loci required for replication and maintenance of plasmids (11.0 kbp pTJS133). Another limitation is that the smaller pRK2-derived plasmids (10.3 kbp pRK252, 7.0 kbp pTJS75 and $5.0 \mathrm{kbp}$ mini-pRK2 replicon vector) have been maintained less stably in Agrobacterium in non-selective conditions $[14,15]$.

\section{1. pRK252-Based Binary Vectors}

A smaller pRK2 derivative $10.3 \mathrm{kbp}$ pRK252 was the backbone of a first binary vectors pBin19 (11.8 kbp) with addition of Streptoccocus faecalis NPTIII gene for bacterial kanamycin resistance, nopaline pTiT37 T-DNA borders, a plant selection marker nos:NPTII:nos, the $\alpha$ complementary region of $\beta$-galactosidase (lacZ' locus) for selection, and polylinker site from M13mp19 [16]. pBI121 (14.7 kbp) and other pBI constructs, and pBIG/ pBIB were based on pBin19 with addition of a new GUS reporter gene 35S:GUS:nos [17,18]. pAGS127 (15.0 kbp) has a pRK252 backbone with the T-DNA region consisting of octopine pTiA6 right border and octopine pTiAch5 left border, a plant selection marker nos:NPTII:ocs, the lac Z' locus and polylinker, and cos site for a large DNA fragment insertion [19].

\section{2. pRK290-Based Binary Vectors}

pRK290 was the first pRK2-derived plasmid developed for a shuttle vector between $E$. coli and $S$. meliloti to study the genetic loci for nodulation and nitrogen fixa- tion of the nitrogen-fixing bacteria [12]. pRK290 was also used as an intermediate vector to transfer a plant gene for the bean seed storage protein phaseolin to TDNA of pTi15955 and then introduce the gene for expression in the genomes of sunflower and tobacco $[8,20]$. A binary vector pOCA18 (24.3 kbp) has the pRK290 backbone and the T-DNA region of octopine pTi right and left borders, a plant selection marker nos:NPTII:ocs, and $\lambda$ cos site for insertion of DNA library of Arabidopsis thaliana [21]. Similarly, pJJ1881 (25.7 kbp) has the pRK290 backbone with octopine pTiA6 right border and pTiAch5 left borders, a plant selection marker nos: NPTII:ocs gene, polylinker, 35S:GUS or SPT:nos (SPT, Streptomycin PhosphoTransferase), or maize transposons Ac or Ds [22]. The pRK290-based pJJ1881 vector derivative was shown to stably maintain DNA fragments over $300 \mathrm{kbp}$ in E. coli [23,24].

\section{3. pTJS75-Based Binary Vectors}

The plasmid pTJS75 was the smallest derivative (7.0 kbp) of pRK2 and used to generate binary vectors pGA471 (15.6 kb) [25,26] and pTRA409 (11.5 kbp) [27]. The vector pGA471 has nopaline pTiT37 right and left borders, a plant selection marker gene nos:NPTII:nos, $\lambda \cos$ site and ColE1 replicon in T-DNA. The vector pTRA409 has the T-DNA with octopine pTi15955 right (with overdrive) and left borders, a plant selection marker gene tml:NPTII:tml and used to test promoter deletion mutants of the bean seed storage protein phaseolin gene.

\section{4. mini-pRK2 Replicon-Based Binary Vectors}

The binary vector pPCV001 (9.2 kbp) has a conditional mini-RK2 replicon (oriV and oriT) and can be maintained in Agrobacterium and E. coli only when co-existed in trans with the trf and tra loci in a helper plasmid pRK2013 or in the E. coli chromosome [14]. The T-DNA region of pPCV001 has nopaline pTiC58 right border and octopine pTiB6S3 left border, a plant selection marker gene nos:NPTII:ocs, and pBR322 sequence for plasmid rescue experiments $[28,29]$. The binary vector pCB301 (5.0 kbp) was constructed by PCR cloning of a mini-pRK replicon (oriV and $\operatorname{trfA}$ ) and bacterial NPTIII kanamycin resistance gene based on DNA sequence of pBin19 [15]. The T-DNA region consists of nopaline pTiT37 right and left borders, nos:BAR:nos plant selection marker gene (Bar, herbicide glufosinate) and pBlueScriptII polylinker for cloning.

\section{Agrobacterium rhizogenes pRi Origin of Replication}

Agrobacterium rhizogenes is a soil-living plant pathogen causing hairy root disease. A large 200 kbp plasmid pRi 
has the T-DNA and virulence region and is responsible for causing the disease phenotype. The origin of replication of pRi plasmid locates within the $8.1 \mathrm{~kb}$ BanHI-11 fragment and can stably coexist with the pTi origin of replication in A. tumefaciens. The binary vector pC22 $(17.5 \mathrm{~kb})$ has the origin of replication of pRiHR1 and ColE1, bacterial resistance gene for ampicilin/carbenicillin or streptomycin/spectinomycin [30]. The T-DNA region of pC22 consists of the right and left borders from octopine pTiB6S3, a plant selection marker gene nos: NPTII:nos, multi-cloning site (BamHI, XbaI) and the $\lambda \cos$ site for in vitro packaging of Arabidopsis thaliana genomic library.

A second binary vector pCGN1547 (14.4 kb) also uses the origin of replication of pRiRH1 and ColE1 and a bacterial resistance gene for gentamycin [31]. The T-DNA region of the vector has the right and left borders of octopine pTiA6, a plant selection marker mas:NPTII: mas, the lacZ' locus and polylinker site from pUC18 for clonig. The stability of binary vectors in Agrobacterium was compared between plasmids with the origin of replication from pRi and pRK2, pCGN1547 and pBin19, respectively. pCGN1547 was much more stable than pBin19 and after 27 generations in non-selective conditions 54\% of Agrobacterium lost the pBin19 while only $1 \%$ lost pCGN1547. Thus, the binary vectors containing the pRi origin of replication has the major advantage in stable maintenance, and a limitation in a low copy number of one or few in cells of Agrobacterium.

\section{Broad Host-Range Origin of Replication from pSa of IncR Incompatability Group}

Wide-host-range origin of replication from pSa derived from a cryptic mini-plasmid P15A in E. coli. The replication locus of pSa ori and rep region is one of the smallest known naturally occurring replicons (2.3 kbp). The replication regions were split into two separate plasmids as two-component binary vector systems to reduce the size of T-DNA-containing plasmids [32]. pGreen0029 (4.6 kbp) contains a bacterial kanamycin resistance gene, pSa origin of replication, and the TDNA with nopalinepTiT37 right (with overdrive) and left borders, and a plant selection marker nos:NPTII:nos. The suplementary plasmid pSoup (9.3 kbp) has a bacterial tetracycline resistance gene and pSa rep region. pSoup must co-exist in Agrobacterium for replication of pGreen. This two-component binary vector system was used to construct LucTrap vectors to generate transcriptional and translational fusion of the firefly luciferase reporter to randomly targetted genes [33]. The stability of binary vectors in Agrobacterium was compared between plasmids with the origin of replication from $\mathrm{pSa}$ and $\mathrm{pRK} 2$, pGreen000 and pBin19, respectively. pGreen000 was less stable than pBin19 and after one-day in non-selective conditions 50\% of Agrobacterium lost the pGreen000 plasmid. Thus, the stable maintenance of pSa-repiconcontaining binary vectors in Agrobacterium is the major limitation for its use when required for a long co-cultivation period of over two days.

A new version of the two-component binary vector system, pCLEAN-G and pCLEAN-S corresponds to pGreen and pSoup, respectively [34]. A new feature is that both plasmids have the T-DNA region delimited by nopaline pTi consensus right and left borders. The T-DNA of pCLEAN-G115 (6.0 kbp) has a plant selection marker gene 35S:HPT:nos, lacZ' selection and polylinker. Supplementary pCLEAN-S166 (11.1 kbp) has a different selection marker nos:HPT:nos in T-DNA (HPT, Hygromycin Phospho Transferase).

\section{Broad Host-Range Origin of Replication from pVS1 of IncP Incompatability Group}

pVS1 is a non-conjugative $29 \mathrm{kbp}$ plasmid of IncP incompatibility group isolated from Psuedomonas aeruginosa. The plasmid was found to replicate in a wide-range of gram-negative bacteria including other Pseudomonas species ( $P$. syringae, $P$. putida) as well as in $A$. tumefaciens and $S$. leguminosarun, but not in E. coli [35]. A pVS1 derivative pME290 contains a $3.7 \mathrm{kbp}$ region for replication and stability gene [36].

Another pVS1 derivative pGV910 contains an 8 kbp fragment for the stability, replication and mobilization gene [37]. The stability of pGV910 in A. tumefaciens GV3101 was compared with that of pRK2 replicon-containing pRK290 [37]. pGV910 was much more stable than pRK290 and after 15 generations in non-selective conditions only less than $0.5 \%$ lost pGV910 while $26 \%$ of Agrobacterium lost the pRK290. Plasmid pVS1 was found compatible with IncP-1 and IncP-4 replicons. Coexistence of pGV910 and pRK290 appeared to increase the stability of pRK290 and after 16 generations in nonselective conditions only $12 \%$ of Agrobacterium lost pRK290.

The origin of replication of pVS1 was defined to a 3.1 kbp fragment for staA, ORF3, repA and oriV by sequence analysis, mutagenesis and maintenance assay in $P$. fluorescens [38]. The coding region of StaA (209 codons) contains two ATP-binding sites and motifs typical of a partitioning protein and is essential for segregational stability. The ORF3 (71 codons) has no apparent similarity with other known proteins but deletion and mutational studies showed the ORF3 is important for segregational stability. The RepA protein with 357 codons shares a strong similarity with other RepA proteins. Mutation from $\mathrm{Ala}_{246}$ to $\mathrm{Val}_{246}$ increased the plasmid copy number from 5.9 to 13.8 copies per chromosome, mutation from 
Asp $_{260}$ to $\mathrm{Asn}_{260}$ reduce the copy number. The oriV locus has the typical sequence organization of origin of replication, a DnaA box, four direct repeats of $21 \mathrm{bp}$ each, an AT-rich region, and a second DnaA box.

The backbone of binary Ti vector pPZP plasmid is the $3.8 \mathrm{~kb}$ fragment of pVS1 origin of replication and the 1.1 kb ColE1 replicon and bom site from pBR322 [39]. pPZP111 (11.8 kb) has the T-DNA region consisting of nopaline pTiT37 right and left borders, a plant kanamycin or gentamycin resistance gene 35S:NPTII or aacC1: 35S, respectively, lacZ' selection and polylinker from pUC18. pPZP111 has a bacterial chloramphenicol resistance gene from pBR325, and pPZP211 (11.9 kb) has a bacterial streptomycin/spectinomycin resistance aadA gene, encoding aminoglycoside-3'-adenyltransferase.

Presently, a series of pCAMBIA plasmids $(9.0 \mathrm{kbp})$ are among the most widely utilized binary $\mathrm{Ti}$ vectors (Genbank accession numbers AF234290-AF234316). The plasmids have the same backbone of pPZP plasmids and their sizes are either 6.2 or $6.4 \mathrm{~kb}$ with a bacterial kanamycin or chloramphenicol resistance genes, respectively. The T-DNA region is delimited by the nopaline pTiT37 right (with overdrive) and left border sequences. Two types of plant selection marker are available as either the kanamycin or hygromycin resistance gene, 35S: NPTII or HPT:35S, respectively. Two $\beta$-glucuronisase reporters are provided, GUS from E. coli $\left(g u s A^{E c o}\right)$ or GUSPlus from Staphylococcus sp. $\left(g u s A^{\text {Ssp }}\right)$. A second reporter green fluorescent protein is also available either as by itself $(g f p)$ or fusion genes with GUS $\left(g u s A^{E c o}: g f p\right.$ or $g f p: g u s A^{E c o}$ ). The lacZa selection with multi-cloning sites for insertion was derived from either pUC18, 8 or 9 .

Modular binary Ti vectors pMODUL and pSAT were developed based on pZP200 (6.7 kbp) as a backbone of the vectors $[40,41]$. The pMODUL vectors took advantage of use of low frequency-occurring enzymes, 13 hexanucleotide and 6 ocatanucleotide restriction sites, and 5 homing endonuclease sites to construct six different expression units in a single construct. Modular pSAT vectors also used 6 octanucleotide restriction endonucleases and Gateway recombination cloning sites for modular assembly of $\mathrm{N}$ - and C-terminal fusions to five different autofluorescent tags [enhanced green (EGFP), yellow (EYFP) and cyan fluorescent proteins ECFP), red autofluorescent protein (DsRed2), and reduced chloride-ionand $\mathrm{pH}$-sensitivity yellow fluorescent protein (CitrineYFP)].

Most recently, a series of smaller high-yielding binary Ti vectors pLSU were constructed to increase the cloning efficiency and plasmid yield in E. coli and A. tumefaciens [42-44]. The size of the binary vector backbone pLSU1 was reduced to $4566 \mathrm{bp}$ with ColE1 replicon (715 bp) for E. coli and VS1 replicon (2654 bp) for A. tumefaciens, a bacterial kanamycin resistance gene (999 bp), and the T-DNA region (152 bp) (Figure 1). The binary Ti vectors with the truncated VS1 replicon were stably maintained with more than $98 \%$ efficiency in A. tumefaciens without antibiotic selection for four days of successive transfers. The transcriptional direction of VS1 replicon can be the same as that of ColE1 replicon (co-directional transcription), or opposite (head-on transcription) as in the case of widely used vectors (pPZP or pCambia). The new pLSU vectors with co-directional transcription yielded in $E$. coli up to four-fold higher transformation frequency than those with the head-on transcription. In $A$. tumefaciens the effect of co-directional transcription is still positive in up to 1.8-fold higher transformation frequency than that of head-on transcription. Transformation frequencies of new vectors are over six-fold higher than those of pCambia vector in A. tumefaciens. DNA yields of new vectors were three to five-fold greater than pCambia in E. coli. Figure 2 illustrates the composition of T-DNA in pLSU1 to 5. pLSU1 is a basic backbone vector with the twelve common restriction sites in TDNA. pLSU2 and 3 have the kanamycin resistance NPTII gene as a plant-selectable marker. pLSU4 and 5 contain the hygromycin resistance HPH gene as a plant-

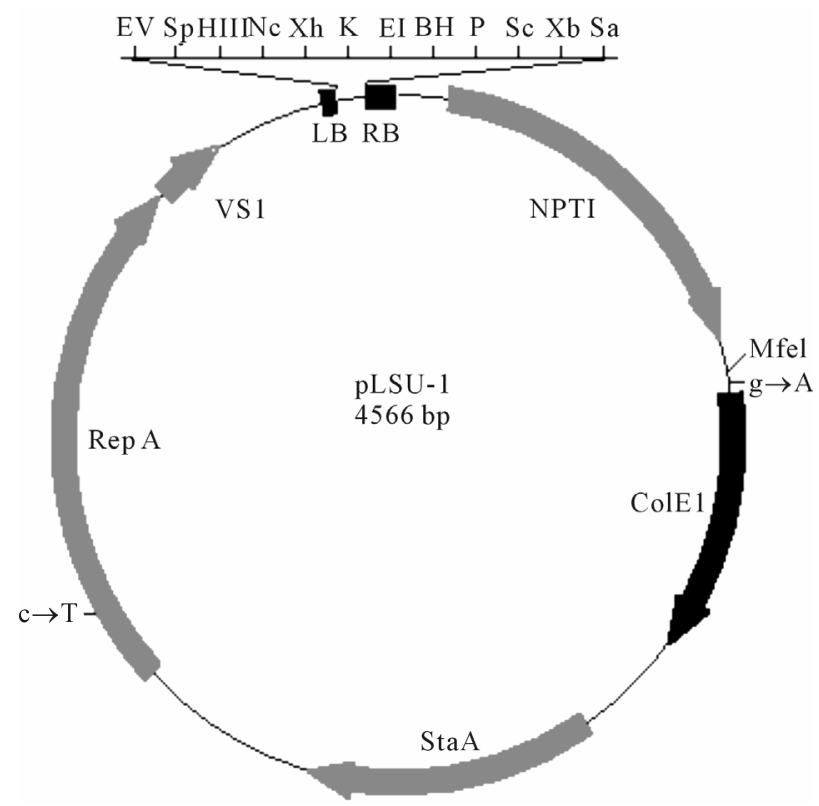

Figure 1. Schematic presentation of backbone structure of binary Ti vector pLSU1 (4566 bp). T-DNA is at the top of figure delimited by the right (RB) and left border (LB) with 12 common restriction endonuclease sites, EcoRV (EV), SphI (Sp), HindIII (HIII), NcoI (Nc), XhoI (Xh), KpnI (K), EcoRI (EI), BamHI (BH), PstI (P), ScaI (Sc, XbaI (Xb), and SacI (Sa). The backbone plasmid include the Neomycin PhosphoTransferase I (NPTI), ColE1 origin of replication (ColE1), Stability region A (StaA), Replication region A (RepA), and VS1 origin of replication (VS1). 

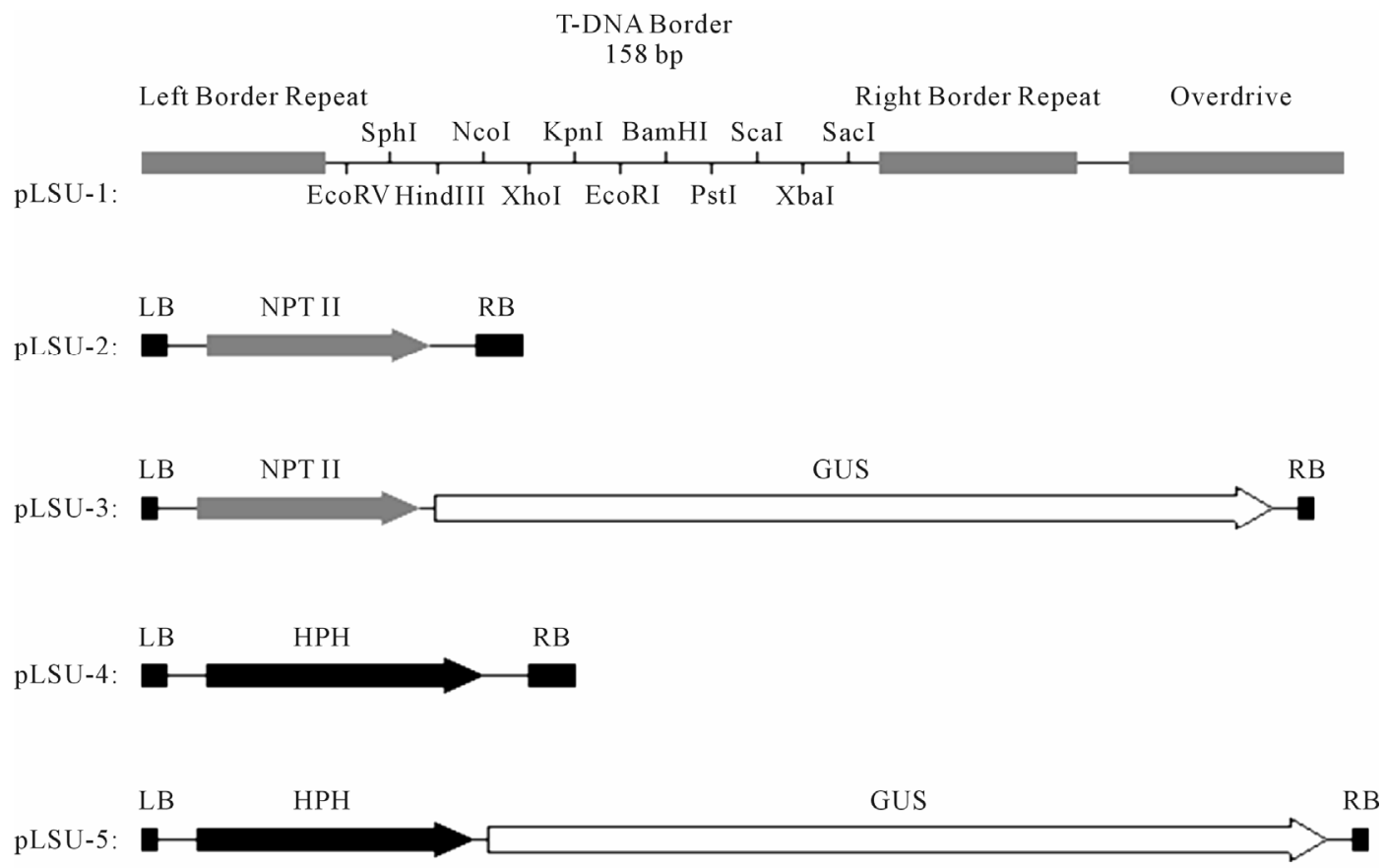

Figure 2. Schematic presentation of the T-DNA region of binary Ti vectors pLSU1 to 5 . pLSU1 is a basic backbone vector with the twelve common restriction sites in T-DNA. pLSU2 and 3 have the Neomycin PhosphoTransferase II gene (NPTII) adjacent to the left border as a plant selection marker for kanamycin resistance. pLSU4 and 5 contain the Hygromycin B Phosphotransferasae gene (HPH) adjacent to the left border as a plant selection marker for hygromycin resistance. pLSU3 and 5 also include the $\beta$-glucuronidase reporter gene (GUS) in addition to the plant selection marker in the T-DNA.

selection marker. pLSU3 and 5 also have the GUS reporter gene in addition to the plant-selectable marker.

To be compatible with the Gateway Technology (Invitrogene), pLSU vectors were modified to include a bacterial tetracycline-resistance gene [42]. The size of the tetracycline resistance gene TetC from pBR322 was reduced to $1468 \mathrm{bp}$ containing $1191 \mathrm{bp}$ of the coding region, 93 bp of 5' upstream, and 184 bp 3'-downstream region. The final size of basic binary vector backbone pLSU11 is 5034 bp. pLSU12 and13 have the kanamycin resistance NPTII gene as a plant selection marker. pLSU14 and 15 contain the hygromycin resistance HPH gene as a plant-selectable marker. pLSU13 and 15 also have the $\beta$-glucuronidase (GUS) reporter gene in addition to the plant selection marker. Constructed also was a mobilizable version of tetracycline-based binary $\mathrm{Ti}$ vector pLSU16 in which the mob function of ColE1 replicon was maintained for mobilization of the binary vector from $E$. coli to $A$. tumefaciens by tri-parental mating. The final size of binary Ti vector backbone pLSU16 is 5580 bp.

\section{Acknowledgements}

The author wishes to acknowledge the financial support partly from the Department of Plant Pathology and Crop Physiology, the College of Agriculture, Louisiana State
University, and from the Louisiana Agriculture Experiment Station, LSU AgCenter.

\section{REFERENCES}

[1] E. F. Smith and C. O. Towsend, “A Plant Tumor of Bacterial Origin,” Science, Vol. 25, No. 643, 1907, pp. 671673. doi:10.1126/science.25.643.671

[2] I. Zaenen, N. Van Larebeke, H. Teuchy, M. Van Montagu and J. Schell, "Supercoiled Circular DNA in Crown-Gall Inducing Agrobacterium Strains," Journal Molecular Biology, Vol. 86, No. 1, 1974, pp. 117-127. doi:10.1016/S0022-2836(74)80011-2

[3] M. D. Chilton, M. H. Drummond, D. J. Merlo, D. Sciaky, A. L. Montoya, M. P. Gordon and E. W. Nester, "Stable Incorporation of Plasmid DNA into Higher Plant Cells: The Molecular Basis of Crown Gall Tumorigenesis," Cell, Vol. 11, No. 2, 1977, pp. 263-271. doi:10.1016/0092-8674(77)90043-5

[4] J. R. Zupan and P. Zambryski, "Transfer of T-DNA from Agrobacterium to the Plant Cell," Plant Physiology, Vol, 107, No. 4, 1995, pp. 1041-1047. doi:10.1104/pp.107.4.1041

[5] J. Sheng and V. Citovsky, "Agrobacterium-Plant Cell DNA Transport: Have Virulence Proteins, Will Travel," Plant Cell, Vol. 8, No. 10, 1996, pp. 1699-1710.

[6] S. B. Gelvin, "Agrobacterium-Mediated Plant Transformation: The Biology behind the 'Gene-Jockeying' Tool," 
Microbiology Molecular Biology Reviews, Vol. 67, No. 1, 2003, pp. 16-37.

[7] P. Zambryski, H. Joos, C. Genetello, J. Leemans, M. Van Montagu and J. Schell, "Ti Plasmid Vector for the Introduction of DNA into Plant Cells without Alteration of Their Normal Regeneration Capacity,” EMBO Journal, Vol. 2, No. 12, 1983, pp. 2143-2150.

[8] N. Murai, D. W. Sutton, M. G. Murray, J. L. Slightom, D. J. Merlo, N. A. Reichert, C. Sengupta-Gopalan, C. A. Stock, R. F. Baker, J. D. Kemp and T. C. Hall, "Phaseolin Gene from Bean Is Expressed after Transfer to Sunflower via Tumor-Inducing Plasmid Vectors,” Science, Vol. 222, No. 4623, 1983, pp. 476-482.

[9] A. Hoekema, P. R. Hirsch, P. J. J. Hooykas and R. A. Schilperoort, “A Binary Plant Vector Strategy Based on Separation of Vir- and T-Region of the Agrobacterium tumefaciens Ti Plasmid,” Nature, Vol. 303, 1983, pp. 179-180. doi:10.1038/303179a0

[10] R. Hellens, P. Mullineaux and H. Klee, "A Guide to Agrobacterium Binary Ti Vectors," Trends in Plant Science, Vol. 5, No. 10, 2000, pp. 446-448.

[11] T. Komori, T. Imayama, N. Kato, Y. Ishida, Y. Ueki and T. Komari, "Current Status of Binary Vectors and Superbinary Vectors,” Plant Physiology, Vol. 145, No. 4, 2007, pp. 1155-1160.

[12] G. Ditta, S. Stanfield, D. Corbin and D. R. Helinski, "Broad Host Range DNA Cloning System for GramNegative Bacteria: Construction of a Gene Bank of Rhizobium meliloti," Proceedings of the National Academy of Sciences of the United States of America, Vol. 77, No. 12, 1980, pp. 7347-7351. doi:10.1073/pnas.77.12.7347

[13] T. J. Schmidhauser and D. R. Helinski, "Regions of Broad-Host-Range Plasmids RK2 Involved in Replication and Stable Maintenance in Nine Species of Gram-Negative Bacteria,” Journal of Bacteriology, Vol. 164, No. 1, 1985, pp. 446-455.

[14] C. Koncz and J. Schell, "The Promoter of TL-DNA Gene 5 Controls the Tissue-Specific Expression of Chimeric Genes Carried by a Novel Type of Agrobacterium Binary Vector," Molecular General Genetics, Vol. 204, No. 3, 1986, pp. 383-396. doi:10.1007/BF00331014

[15] C. Xiang, P. Han, I. Lutziger, K. Wang and D. J. Oliver, "A Mini Binary Vector Series for Plant Transformation," Plant Molecular Biology, Vol. 40, No. 4, 1999, pp. 711717. doi:10.1023/A:1006201910593

[16] M. Bevan, "Binary Agrobacterium Vectors for Plant Transformation,” Nucleic Acids Research, Vol. 12, No. 22, 1984, pp. 8711-8721. doi:10.1093/nar/12.22.8711

[17] R. A. Jefferson, “Assaying Chimeric Genes in Plants: The GUS Gene Fusion System,” Plant Molecular Biology Reporter, Vol. 5, No. 4, 1987, pp. 387-405. doi:10.1007/BF02667740

[18] D. Becker, "Binary Vectors Which Allow the Exchange of Plant Selectable Markers and Reporter Genes,” Nucleic Acid Research, Vol. 18, No. 1, 1990, p. 203. doi:10.1093/nar/18.1.203

[19] P. Van den Elzen, K. Y. Lee, J. Townsend and J. Bed- brook, "Simple Binary Vectors for DNA Transfer to Plant Cells,” Plant Molecular Biology, Vol. 5, No. 3, 1985, pp. 149-154. doi:10.1007/BF00015678

[20] C. Sengupta-Gopalan, N. A. Reichert, R. F. Baker, T. C. Hall and J. D. Kemp, "Developmentally Regulated Expression of the $\beta$-Phaseolin Gene in Tobacco Seed," Proceedings of the National Academy of Sciences of the United States of America, Vol. 82, No. 10, 1985, pp. 3320-3324. doi:10.1073/pnas.82.10.3320

[21] N. E. Olszewski, F. B. Martin and F. M. Ausubel, "Specialized Binary Vector for Plant Transformation; Expression of the Arabidopsis thaliana AHAS Gene in Nicotiana tabacum," Nucleic Acids Research, Vol. 16, No. 22, 1988, pp. 10765-10782. doi:10.1093/nar/16.22.10765

[22] J. D. G. Jones, L. Shlumukov, F. Carland, J. English, S. R. Scofield, G. J. Bishop and K. Harrison, "Effective Vectors for Transformation, Expression of Heterologous Genes, and Assaying Transposon Excision in Transgenic Plants," Transgenic Research, Vol. 1, No. 6, 1992, pp. 285-297. doi:10.1007/BF02525170

[23] A. F. Bent, B. N. Kunkel, D. Dahlbeck, K. L. Brown, R. Schmidt, J. Giraudat, J. Leung and B. J. Staskawicz, "RPS2 of Arabidopsis thaliana: A Leucine-Rich Repeat Class of Plant Disease Resistance Genes,” Science, Vol. 265, No. 5180, 1994, pp. 1856-1860. doi:10.1126/science.8091210

[24] Q. Tao and H.-B. Zhang, "Cloning and Stable Maintenance of DNA Fragments over $300 \mathrm{~kb}$ in Escherichia coli with Conventional Plasmid-Base Vectors,” Nucleic Acid Research, Vol. 26, No. 21, 1998, pp. 4901-4909. doi:10.1093/nar/26.21.4901

[25] G. An, B. D. Watson, S. Stachel, M. P. Gordon and E. W. Nester, "New Cloning Vehicles for Transformation of Higher Plants,” EMBO Journal, Vol. 4, No. 2, 1985, pp. 277-284.

[26] G. An, "High Efficiency Transformation of Cultured Tobacco Cells,” Plant Physiology, Vol. 79, No. 2, 1985, pp. 568-570. doi:10.1104/pp.79.2.568

[27] M. D. Burow, P. Sen, C. A. Chlan and N. Murai, "Developmental Control of the $\beta$-Phaseolin Gene Requires Positive, Negative, and Temporal Seed-Specific Transcriptional Regulatory Elements and Negative Element for Stem and Root Expression," Plant Journal, Vol. 2, No. 4, 1992, pp. 537-548. doi:10.1111/j.1365-313X.1992.00537.X

[28] C. Koncz, N. Martini, R. Mayerhofer, Z. Koncz-Kalma, H. Korber, G. Redei and J. Schell, "High-Frequency TDNA-Mediated Gene Tagging in Plants," Proceedings of the National Academy of Sciences of the United States of America, Vol. 86, No. 21, 1989, pp. 8467-8471. doi:10.1073/pnas.86.21.8467

[29] B. Reiss, C. Koncz, I. Moore and J. Schell, "A Family of Binary Gene Vectors with Low Inter-Transformant Variation,” Plant Physiol. (Life Sci. Adv.), Vol. 13, 1994, pp. 143-149.

[30] C. Simoens, T. Alliotte, R. Mendel, S. Muller, J. Schiemann, M. van Lijsebettens, J. Schell, M. van Montagu and D. Inze, “A Binary Vector for Transferring Genomic 
Libraries to Plants," Nucleic Acids Research, Vol. 14, No. 20, 1986, pp. 8073-8090. doi:10.1093/nar/14.20.8073

[31] K. E. McBride and K. D. Summerfelt, "Improved Binary Vectors for Agrobacterium-Mediated Plant Transformation,” Plant Molecular Biology, Vol. 14, No. 2, 1990, pp. 269-276. doi:10.1007/BF00018567

[32] R. P. Hellens, E. Z. Edwards, N. R. Leyland, S. Bean and P. M. Mullineaux, "pGreen: A Versatile and Flexible Binary Ti Vectors for Agrobacterium-Mediated Plant Transformation,” Plant Molecular Biology, Vol. 42, No. 6, 2000, pp. 819-831. doi:10.1023/A:1006496308160

[33] L. I. A. Calderon-Villalobos, C. Kuhnle, H. Li, M. Rosso, B. Weisshaar and C. Schwechheimer, "LucTrap Vectors Are Tools to General Luciferase Fusions for the Quantification to Transcript and Protein Abundance in Vivo," Plant Physiology, Vol. 141, No. 1, 2006, pp. 3-14. doi:10.1104/pp.106.078097

[34] V. Thole, B. Worland, J. W. Snape and P. Vain, "The pCLEAN Dual Binary Vector System for Agrobacterium-Mediated Plant Transformation," Plant Physiology, Vol. 145, No. 4, 2007, pp. 1211-1219. doi:10.1104/pp.107.108563

[35] Y. Itoh, J. M. Watson, D. Haas and T. Leisinger, "Genetic and Molecular Characterization of the Pseudomonas Plasmid pVS1,” Plasmid, Vol. 11, No. 3, 1984, pp. 206-220. doi:10.1016/0147-619X(84)90027-1

[36] Y. Itoh and D. Haas, "Cloning Vectors Derived from the Pseudomonas Plasmid pVS1,” Gene, Vol. 36, No. 1-2, 1985, pp. 27-36. doi:10.1016/0378-1119(85)90066-6

[37] G. Van den Eede, R. Deblaere, K. Goethals, M. Van Montagu and M. Holsters, "Broad Host Range and Promoter Selection Vectors for Bacteria That Interact with Plants," Molecular Plant-Microbe Interactions, Vol. 5, No. 3, 1992, pp. 228-234. doi:10.1094/MPMI-5-228

[38] S. Heeb, Y. Itoh, T. Nishijyo, U. Schnider, C. Keel, J. Wade, U. Walsh, F. O'Gara and D. Haas, "Small, Stable Shuttle Vectors Based on the Minimal pVS1 Replicon for
Use in Gram-Negative, Plant-Associated Bacteria," Molecular Plant-Microbe Interactions, Vol. 13, No. 2, 2000, pp. 232-237. doi:10.1094/MPMI.2000.13.2.232

[39] P. Hajdukiewicz, Z. Svab and P. Maliga, "The Small, Versatile $p P Z P$ Family of Agrobacterium Binary Vectors for Plant Transformation,” Plant Molecular Biology, Vol. 25, No. 6, 1994, pp. 989-994. doi:10.1007/BF00014672

[40] I. J. W. M. Goderis, M. F. C. De Bolle, I. E. J. A. Francois, P. F. J. Wouters, W. F. Broekaert and B. P. A. Cammue, "A Set of Modular Plant Transformation Vectors Allowing Flexible Insertion of up to Six Expression Units,” Plant Molecular Biology, Vol. 50, No. 1, 2002, pp. 17-27. doi:10.1023/A:1016052416053

[41] T. Tzfira, G. W. Tian, B. Lacroix, S. Vyas, J. Li, Y. Leitner-Dagan, A. Krichevsky, T. Taylor, A. Vainstein and V. Citovsky, "pSAT Vectors: A Modular Series of Plasmids for Autofluorescent Protein Tagging and Expression of Multiple Genes in Plants,” Plant Molecular Biology, Vol. 57, No. 4, 2005, pp. 503-516. doi:10.1007/s11103-005-0340-5

[42] S. Lee, "New Binary Ti Vectors with Co-Directional Replicons for Agrobacteium tumefaciens-Mediated Transformation of Higher Plants," Ph.D. Thesis, Louisiana State University, Baton Rouge, 2011.

[43] S. Lee, G. Su, E. Lasserre, M. A. Aghazadeh and N. Murai, "Smaller High-Yielding Binary Ti Vectors pLSU with Co-Directional Replicons for Agrobacterum tumefaciens-Mediated Transformation of Higher Plants," Plant Science, Vol. 187, 2012, pp. 49-58.

[44] G. Su, S. Park, S. Lee and N. Murai, "Low Co-Cultivation Temperature at $20^{\circ} \mathrm{C}$ Resulted in the Reproducible Maximum Increase in Both the Fresh Weight Yield and Stable Expression of GUS Activity after Agrobacterium tumefaciens-Mediated Transformation of Tobacco Leaf Disks," American Journal of Plant Sciences, Vol. 3, No. 4, 2012, pp. 537-545. 